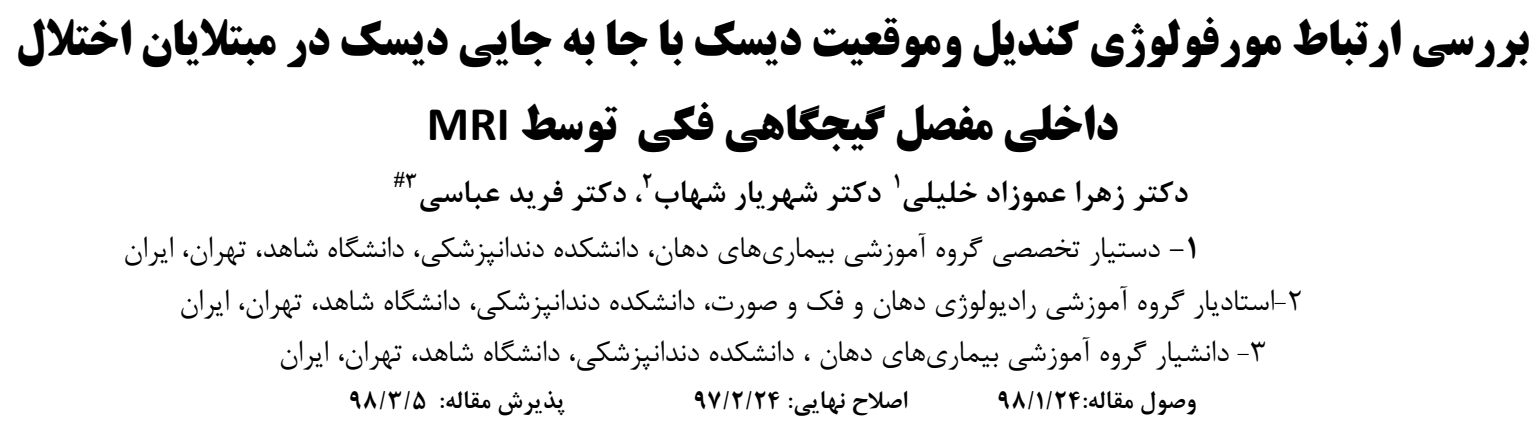

\title{
Correlation between condyle morphology and disk position of disc displacement in patients with TMJ internal derangements by magnetic resonance imaging
}

\author{
Zahra Amoozad khalili ${ }^{1}$, Shahriyar Shahab ${ }^{2}$, Farid Abbasi ${ }^{3 \dagger}$
}

${ }^{1}$ Resident, Department of Oral Medicine, Faculty of Dentistry, Shahed University, Tehran, Iran, E-mail: Zahra_amouzad_kh@yahoo.com ${ }^{2}$ Assistant Professor, Department of Oral and Maxillofacial Radiology, Faculty of Dentistry, Shahed University, Tehran, Iran. ${ }^{3}$ Associate Professor, Department of Oral Medicine, Faculty of Dentistry', Shahed University, Tehran, Iran,

Received: 14 April 2019; Accepted: 27 June 2019

\section{Abstract}

Background and Aims :The most frequent cause of TMJ dysfunction is internal derangement which that largely involves the function of the articular disc. Anterior disc displacement (ADD) is one of the major findings in TMJ internal derangement.

Since the importance of knowledge of its etiology and also the role of all structural indicators association with TMD was not evaluated, in this research was investigated Correlation between TMJ structure and disc displacement.

Materials and Methods: This study was done based on case-control method. 31 Joints with TMJ internal derangements and 57 normal joint Were examined. The two groups of clients were matched in age, sex , Economic and social situation. MRI finding was Disk position in Open and closed mouth and condyle morphology coronal and axial view.MRI findings were Disk position in Open and closed mouth and condyle morphology coronal and axial view. The data were analyzed using Chi-square test and Fisher's test.

Results: Patients with TMJ internal derangement (ID), In all three groups inchiding disk displacement with reduction(DDWR), disk displacement without reduction(DDWOR), anterior disc displacement(ADD), was encountered more frequently in Anterior, Anterior-inferior disk position in closed mouth,A statistically significant correlation was found $(\mathrm{P}<0.001)$. Also no significant difference was found in measurements between the three groups, for condyle morphology in coronal and axial view. $(\mathrm{P}>0.4)$

Conclusion: It seems , Anterior disc displacement (ADD) is correlated Anterior, Anterior-inferior disk position in closed mouth But There is no correlation between Anterior disc displacement (ADD) And condyle morphology in coronal and axial view.

Key Words: TMJ, MRI, Mandibular Condyle, Disc Displacement

*Corresponding Author: f.abasi@shahed.ac.ir

J Res Dent Sci. 2019; 16 (2):110-116 
سابقه و هدف: اختلالات داخلى(ID)، شايعترين علت اختلال مفصل كيجكاهى فكى(TMD) مى باشد كه به طور گسترده اى

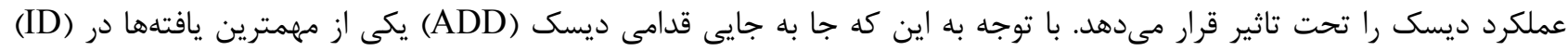

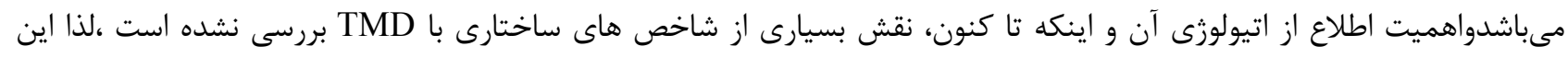

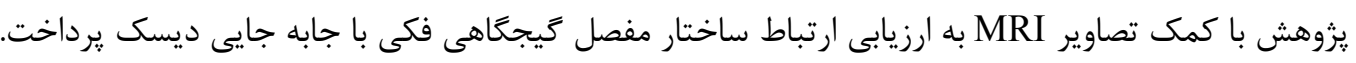

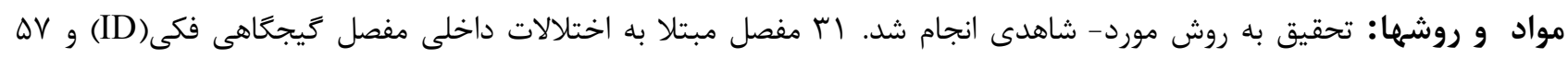

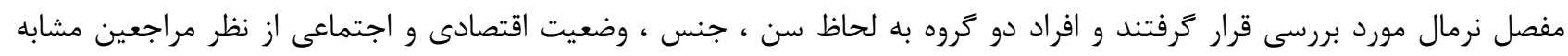

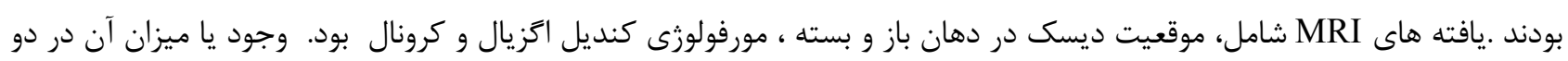

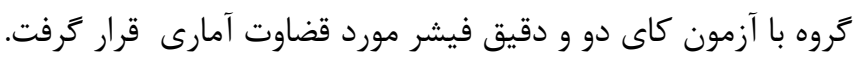

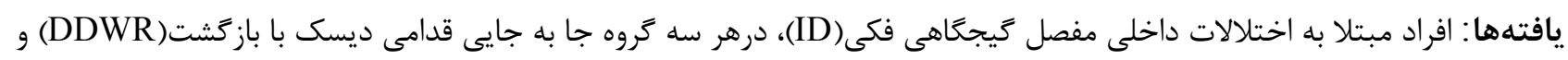

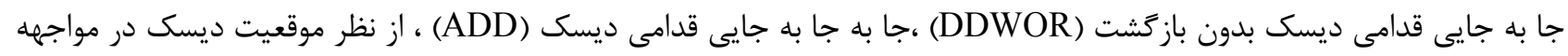

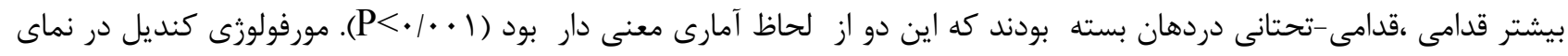

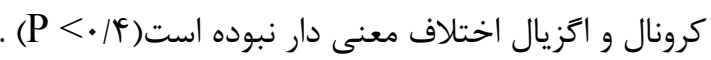

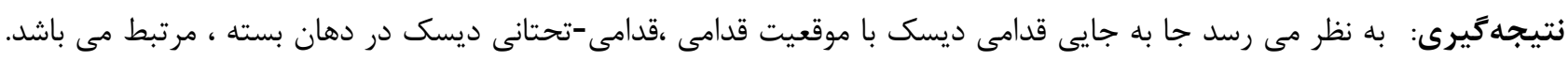

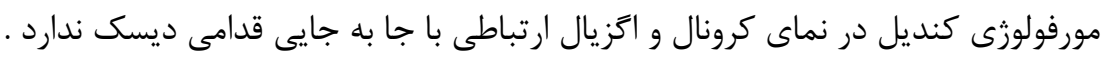
كلمات كليدى: MRI TMJ ، كنديل منديبل، جابهجايى ديسك

مقدمهه:

يكى از عواملى كه ممكن است در ابتلا به TMD نقش

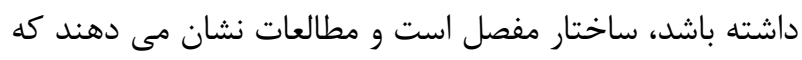

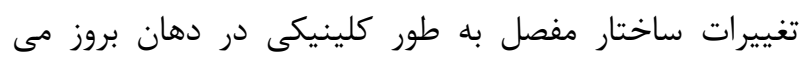

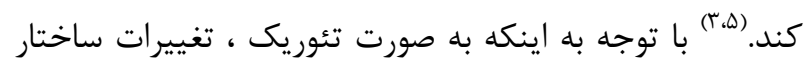

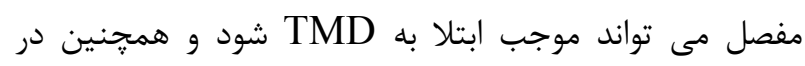

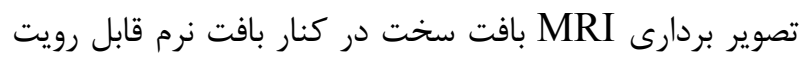

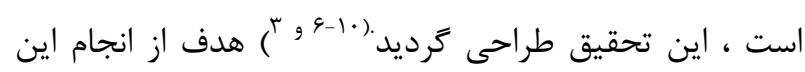
تحقيق بررسى ارتباط مورفولوزى كنديل و موقعيت ديسك با جا به جايى ديسك در مبتلايان اختلالات داخلى مفصل

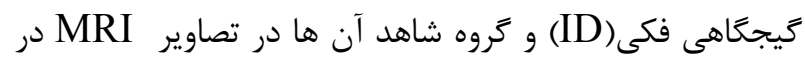
مراجعين به دوكلينيك راديولوزى يزشكى در سال لو بود.

\section{مواد و روش ها}

تحقيق به روش مورد- شاهدى انجام شد. گروه مورد،

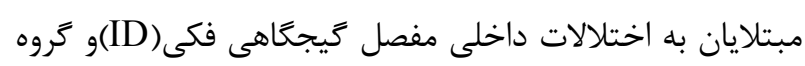

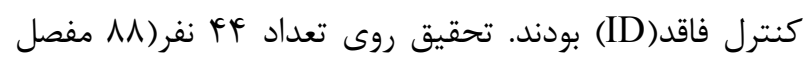

يكى از نكرانيها و دغدغه هاى جامعه و به ويزه دندانيزشكان مراجعه بيماران مبتلا به مشكلات تميورومنديبولار

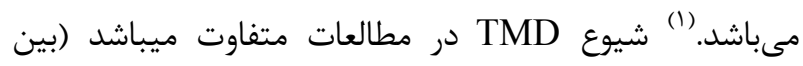
VA-IV صورتى -دهانى امريكا، TMD را اينكَونه تعريف مينمايد: مشكل

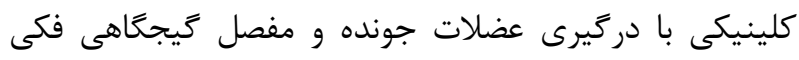

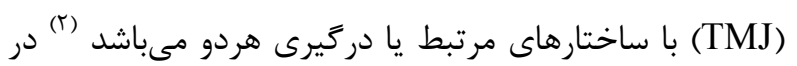

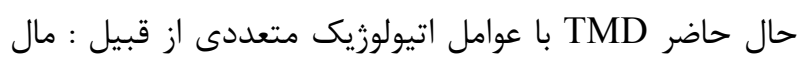
اكلوزن، اختلال داخلى مفصل گيجكاهى ، مشكل ديسك، مشكل دندانى، استرس، تروما، پارافانكشن، سن، جنس مرتبط

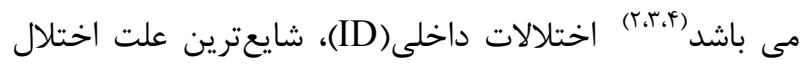
مفصل كيجكاهى فكى(TMD) مى باشد كه جا به جايى قدامى

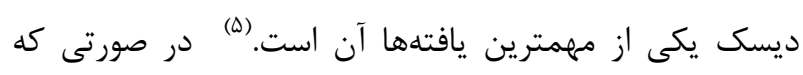

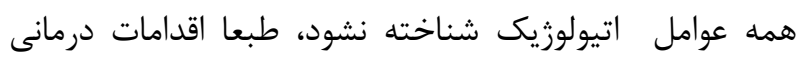
ناموفق بوده و تداوم بيمارى در بيماران مشكلات را ييشرفته تر

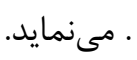




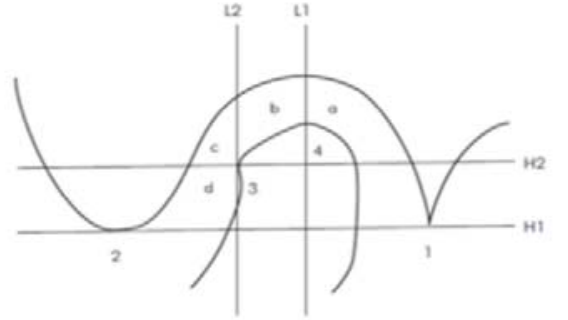

a- فوقانى

b- فوقانى قدامى

C- تلداميى

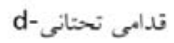

شكل ا: موقعيت ديسك در دهان بسته

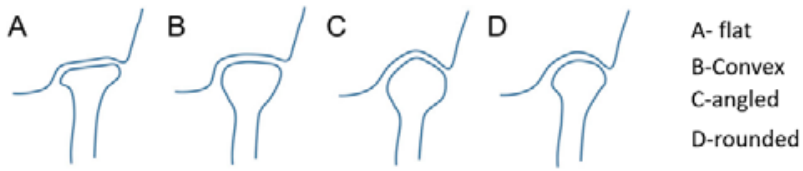

شكل r- مورفولوزى كنديل در نماى كرونالى
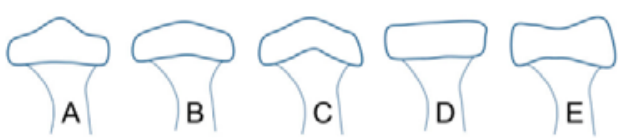

A- flat-convex

B-biconvex

C-concave-convex

D-flat

E-biconcave

شكل - مورفولوزى كنديل در نماى آتزيال

\section{MRI تكنيك}

General Electric, Milwaukee, ) توسط دستخاه MRI 1/ه ، GE signa scanner (WI signa; GE ) به قطر \&/ TMJ surface coil max (medical systems maximal (intercuspal position انجام گرديد. تصاوير sagittal در دهان باز و بسته با (TE28/2ms ،TR1500ms) ، proton density (PD) و بهان intersection gap ب با ضخامت FOV(14×14cm) ه/• ميلىمتر تهيه گرديد. تصاوير آكزيال در دهان بسته و (TE81/9ms ، TR4120ms) (T2 W1) intersection gap ب با ضخامت FOV 3 (24×24cm) COR FRFSE م تهيه كرديد. تصاوير كرونال 0/5 mm
(TMJ كه آ مفصل با اختلالات داخلى مفصل گيجكاهى فكى(ID)بودند و DV مفصل نرمال مورد بررسى قرار ترفتند و افراد دو گروه به لحاظ سن، جنس، وضعيت اقتصادى و اجتماعى از نظر مراجعين مشابه بودند. ضمن آنكه افراد زير 11 سال و آنومالىهاى كنديل و داراى سابقه تروما از جامعه حذف شدند. افراد مبتلا بهTMD با (درد، آسيمترى، محدوديت باز كردن، انحراف فك حين باز كردن، كليك و ديخر صداهاى

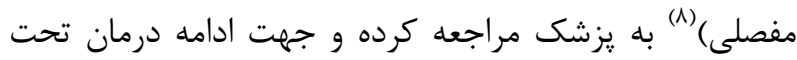
تصويربردارى MRI قرار گرفته و داراى اختلالات داخلى مفصل كيجكاهى فكى(ID) واختلال جابهجايى ديسك بودند، مورد

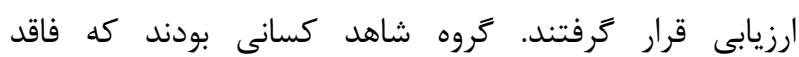
مشكل(ID) بوده و مواردى كه داوطلبانه از آنها MRI تهيه كرديد. تصاوير MRI هر دو گروه از دو كلينيك راديولوزى مونى يزشكى فراهم كرديد و توسط دو راديولوزيست مورد بررسى قرار ترفت. يافته هاى MRI شامل موقعيت ديسك در دهان باز و بسته و همجنين مورفولوزى كنديل در نماى كرونال و اتزيال مىباشد. موقعيت ديسك در دهان بازدر جهار دسته نرمال

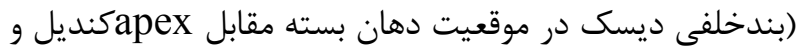
بند ميانى در موقعيت دهان باز بين كنديل و آرتيكولار اميننس)، جا به جايى قدامى با بازَشت DDWR (بند خلفى دانى

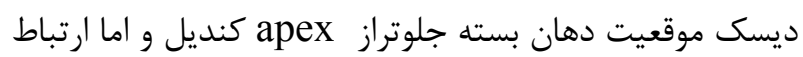
ديسك-كنديل در موقعيت دهان باز مانند نرمال)، جابهجايى بpex بند مDWOR بند خلفى ديسك جلوتراز كنديل در موقعيت دهان باز و بسته)، جابهجايى خلفى PD (َّير افتادن ديسك و عقب رفتن و قراركيرى آن در رابطه مونه

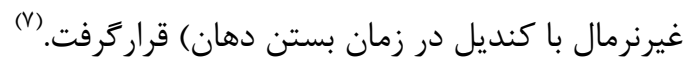
همجنين موقعيت ديسك در دهان بسته(فوقانى،

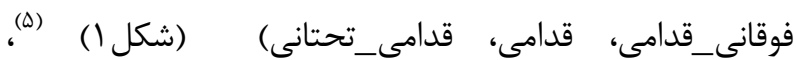
مورفولوزى كنديل كرونال(flat، convex،

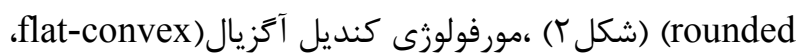
(شكل (biconcave ،flat ،concave-convex ،biconvex

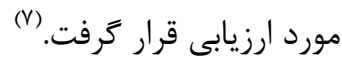


توزيع نمونه ها بر حسب اختلال جا به جايى ديسك ( سه زير مجموعه DDWR و DDWOR و DDD) و به تفكيك موقعيت ديسك در دهان بسته در جدول ا، ارايه شده است و نشان

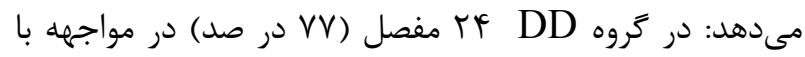
موقعيت ديسك قدامى و قدامى - تحتانى بودند و در گروه نرمال يك مفصل (r درصد) مواجهه بودند (I<) (P< از نظر شاخص DDWR در بيماران (FF درصد) و در گروه نرمال بود ، اين اختلاف نيز معنى دار بود.( ا . • (PV) توزيع نمونه ها بر حسب اختلال جا به جايى ديسك ( سه زير مجموعه DDWR و و DDWOR) و به تفكيك مورفولوزى كنديل نماى كرونال و اتزيال در جدول r ،ارايه شده است و نشان مى دهد اختلاف مورفولوزى كنديل از نماى

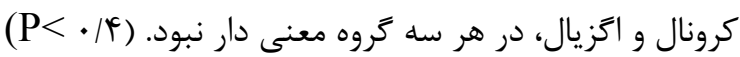

(T2 در دهان بسته (TR4260ms) ، و (TE81/2ms) و intsection با ضخامت سميلى متر و FOV(24×24cm) gap 1 mm كنديل و موقعيت ديسك با اختلال جابهجايى ديسك با و بدون بازگشت، نسبت به گروه شاهد بررسى گرديد. بدين منظور از دو آزمون آمارى كايدو و فيشر استفاده شد.

يافتهها:

در اين تحقيق، 19 بيمار (F مرد و ها زن) در گروه مبتلا به

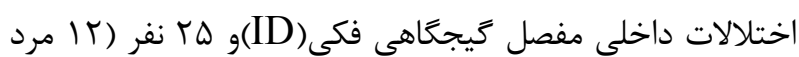
و با زن) در گروه سالم بررسى شدند. سن در گروه بيماران

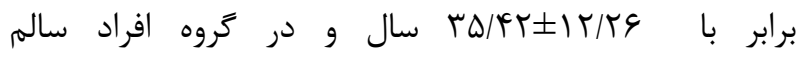
. $F \cdot|\Delta r \pm| \& / F r$

جدول ا توزيع نمونه ها بر حسب گروه اختلال جا به جايى ديسك و نرمال به تفكيك موقعيت كنديل در دهان بسته

\begin{tabular}{|c|c|c|c|c|c|c|}
\hline \multicolumn{3}{|c|}{ كروه مورد } & \multicolumn{2}{|r|}{ كروه شاهد } & \multirow{3}{*}{ مشخصه ها } & \multirow{3}{*}{ رديف و مشخصات } \\
\hline $\begin{array}{l}\text { TOTAL } \\
\text { تعداد (درصد) }\end{array}$ & $\begin{array}{c}\text { PD } \\
\text { تعداد (درصد) }\end{array}$ & $\begin{array}{l}\text { DDWOR } \\
\text { تعداد (درصد) }\end{array}$ & $\begin{array}{c}\text { DDWR } \\
\text { تعداد (درصد) }\end{array}$ & $\begin{array}{l}\text { NORMAL } \\
\text { تعداد (درصد) }\end{array}$ & & \\
\hline (آمفصل) & (كفصل) & (· • (مفصل) & (9فصل) & (مفصل (DV) & & \\
\hline$r Y / \varphi(V)$ & $1 \cdots(r)$ & $\cdot(\cdot)$ & $\Delta \Delta / \xi(\Delta)$ & $9 \Lambda / Y(\Delta \&)$ & فوقانى و فوقانى_ قدامى & S \\
\hline$V V / F(Y Y)$ & $\cdot(\cdot)$ & $1 \cdots(r \cdot)$ & $f \mathcal{F} / f\left(\varphi^{\varepsilon}\right)$ & $1 / \wedge(1)$ & قدامى و قدامى _تحتانى & دهان بسته \\
\hline
\end{tabular}


جدول ז:توزيع نمونه ها بر حسب كروه اختلال جا به جايى ديسك و نرمال به تفكيك مورفولوزى كنديل نماى كرونال و اكزيال

\begin{tabular}{|c|c|c|c|c|c|c|}
\hline & & 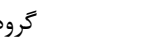 & & تروه شاهد & \multirow{3}{*}{ مشخصه } & \multirow{3}{*}{ رديف و مشخصات متغير } \\
\hline $\begin{array}{c}\text { TOTAL } \\
\text { تعداد (درصد) }\end{array}$ & $\begin{array}{c}\text { PD } \\
\text { تعداد (درصد) }\end{array}$ & $\begin{array}{l}\text { DDWOR } \\
\text { تعداد (درصد) }\end{array}$ & $\begin{array}{c}\text { DDWR } \\
\text { تعداد (درصد) }\end{array}$ & $\begin{array}{l}\text { NORMAL } \\
\text { تعداد (درصد) }\end{array}$ & & \\
\hline مفصل I|r & مفصل r & مفصل ·r & مفصل 9 & مفصل DV & & \\
\hline $\mid 9 / 1(1)$ & $\cdot(\cdot)$ & $r \Delta(\Delta)$ & $\cdot(\cdot)$ & $\operatorname{lf}(\Lambda)$ & flat & \multirow{4}{*}{ مورفولوزى كنديل دهان بسته كرونال } \\
\hline rN/V(IT) & $1 \cdots(r)$ & $r \Delta(\Delta)$ & $\Delta \Delta / \mathcal{G}(\Delta)$ & $Y \Delta / \varphi(\Gamma \varphi)$ & convex & \\
\hline$r \Delta / \Delta(1)$ & $\cdot(\cdot)$ & $r \Delta(V)$ & $F F / F(\mathcal{F})$ & $T F / q(\mid F)$ & angled & \\
\hline$q / V(\Gamma)$ & $\cdot(\cdot)$ & $1 Q(r)$ & $\cdot(\cdot)$ & $10 / \Lambda(9)$ & rounded & \\
\hline$G \psi / \Delta(Y \cdot)$ & $1 \cdots(r)$ & $4 \cdot(I r)$ & $\operatorname{sq/V}(9)$ & $V \backslash / 9(f) 1)$ & $\begin{array}{c}\text { Flat- } \\
\text { biconvex }\end{array}$ & \multirow{2}{*}{ مورفولوزى كنديل دهان بسته آززيال } \\
\hline$r \Delta / \Delta(11)$ & $\cdot(\cdot)$ & $f \cdot(\Lambda)$ & 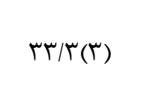 & $r N / /(19)$ & $\begin{array}{c}\text { Flat- } \\
\text { biconcave }\end{array}$ & \\
\hline
\end{tabular}

در مطالعه ما از لحاظ مورفولوزى كنديل، در هر سه گروه DD و DDWOR،DDWR

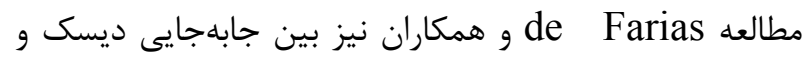

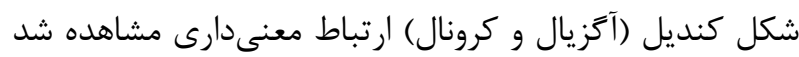

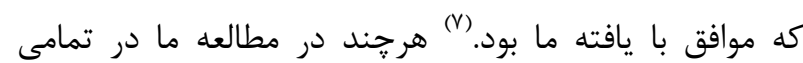
كروهها، شكل biconvex بيشتر مشاهده شد، اما اين اختلاف

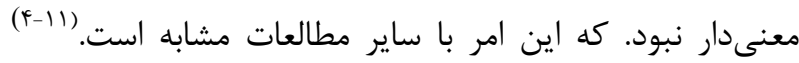

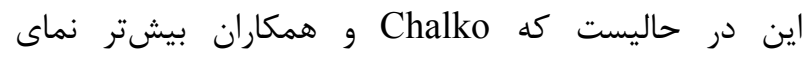

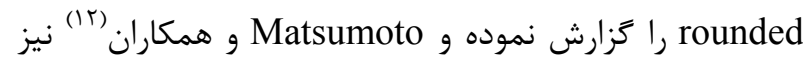

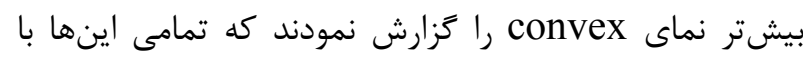

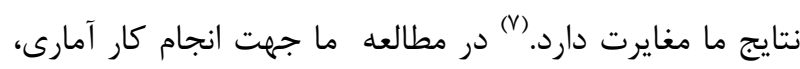

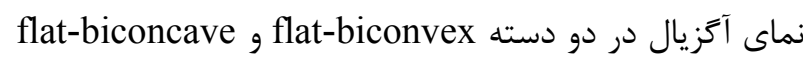

$$
\text { مورد بررسى قرار كرفت. }
$$
در اين مطالعه از تركيب يلن آكزيال، كرونال و ساجيتال در جهت ارزيابى مورفولوزى كنديل ارزيابى شدهاست وعلىرغم

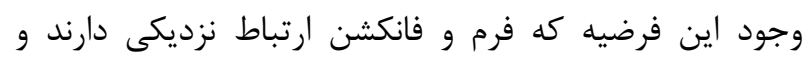
بنابراين با تغيير موفولوزى كنديل، موقعيت ديسك نيز بايد

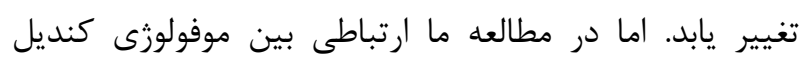

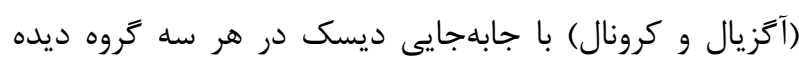

تحقيق نشان داد كه ،جا به جايى قدامى ديسك در هر سه كروه با موقعيت قدامى ،قدامى-تحتانى ديسك در دهان بسته

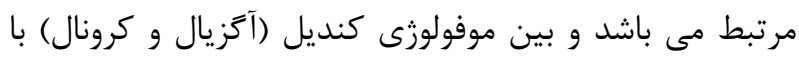
جابهجايى ديسك ارتباطى وجود ندارد . در مطالعه ما، از لحاظ موقعيت ديسك در دهان بسته، موقعيت قدامى-تحتانى ديسك در هر سه گروه DDWR، DDWR و DD در مقايسه با گروه نرمال، داراى اختلاف بود معنىدار

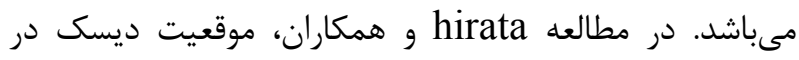

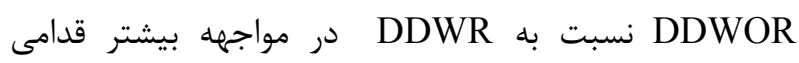

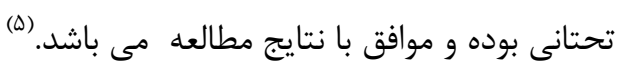

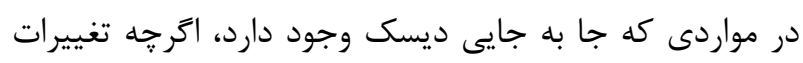
ساختارى درسر كنديل مشاهده نمى گردد اما قابليت جا به به درديه جايى آن به مرور زمان افزايش مى يابد و به دنبال آن منجر به مدريه جا به جايى بيشتر كنديل بر اساس تغيير شكل بيشتر ديسك

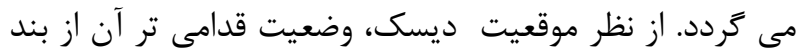
خلفى در مقايسه با موقعيت فوقانى ، ارتباط بيشترى با جا به

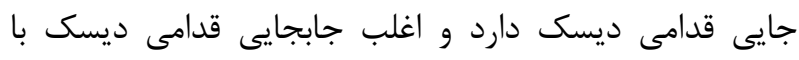
دفورميتى بيشتر آن مرتبط مىباشد. 


\section{نتيجه}

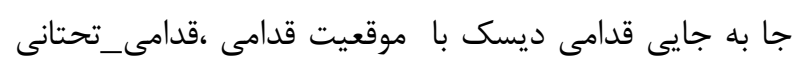

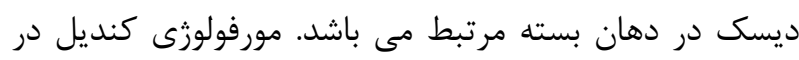

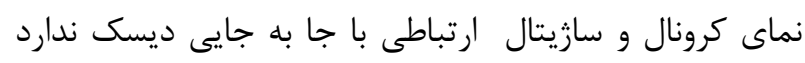

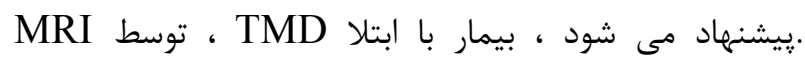

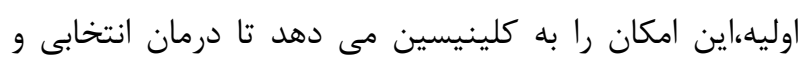

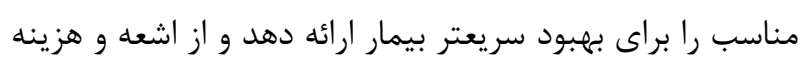
بكاهد.

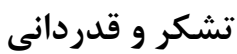

بدينوسيله از راهنمايىهاى ارزشمند جناب آقاى مهندس ناصر

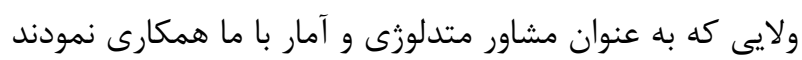

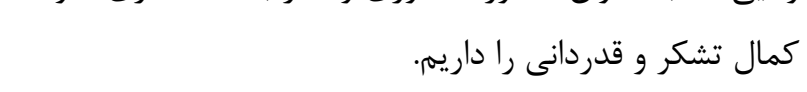

نشد. تئورىهاى مختلفى مورفولوزى كنديل را توضيح مىدهد، از جمله نيروهاى اكلوزالى بيش از حد، تنوع آناتومى و يروسه جويدن وابسته مىباشد. (Ir.V) از نقاط ضعف مطالعه ما دسترسى تعداد نمونه كم و همراه نبودن بالينى بيمار با تصاوير مى باشد و از نقاط قوت آن مان

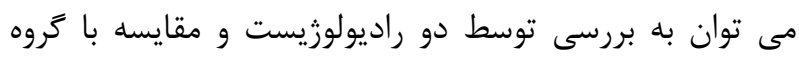
كنترل را اشاره نمود. مطالعات آتى با حجم نمونه بيشتر ، مرنى بررسى همزمان كلينك و كرافى بيماران و افراد نرمال و مقايسه MRI و ساير مداليته هاى تصويربردارى TMJ انجام كردد. 


\section{References:}

1.I Ogura, T Kaneda, S Mori, M Sakayanagi, M Kato. "Magnetic resonance characteristics of temporomandibular joint disc displacement in elderly patients. Dentomaxillofacial Radiology 2012; 41(2): $122-125$.

2. A. H. Chalkoo and Z. A. Bhat, "MRI characteristics of disc displacement of temporomandibular disorders and its correlation with clinical findings in symptomatic and asymptomatic subjects. International Journal of Applied Dental Sciences 2017;3(2):80-5.

3. eghan K, Murphy, BE, Regina F, MacBarb, BS, Mark E. Wong, Kyriacos A. Athanasiou, PE. Temporomandibular Joint Disorders: A Review of Etiology, Clinical Management, and Tissue Engineering Strategies. Oral Maxillofac Implants 2013; 28(6):393-414.

4. S. O. Basat, M. Surmeli, O. Demirel, F. Ceran, F. . A. Saydam, K. Basaran, "Assessment of the Relationship Between Clinicophysiologic and Magnetic Resonance Imaging Findings of the Temporomandibular Disorder Patients. The Journal of Craniofacial Surgeryvol 2016; 1946-50.

5. F. H. Hirata, A. S. Guimarães, J. X. de Oliveira, C. R. Moreira, E. T. T. Ferreira, M. G. P. Cavalcanti, "Evauation of TMJ articular eminence morphology and disc patterns in patients with disc displacement in MRI. Braz Oral Res 2007;21(3): 265-71.

6. A. Ozkan, H. A. Altug, M. Sencimen B. Senel, "Evaluation of Articular Eminence Morphology and Inclination in TMJ Internal Derangement Patients with MRI," Int. J.Morphol 2012 30(2): 740-4.

7. de Farias JFG, Melo SLS, Bento PM, Oliveira LSAF, Campos PSF, de Melo DP. Correlation between temporomandibular joint morphology and disc displacement by MRI. Dentomaxillofac Radiol 2015; 44: 20150023.

8. R Matsubara, Y. Yanagi, K Oki, M Hisatomi, K C. P. Santos, O B Babatunde, M Fujita, S Okada, S Minagi, J Asaumi. Assessment of MRI findings and clinical symptoms in patients with temporomandibular joint disorders. Dento maxillo facial radiology 2018; 47(4): 20170412.

9. C. Gil, K. Santos, M. Dutra, S. Kodaira ,J. Oliveira. MRI analysis of the relationship between bone changes in the temporomandibular joint and articular disc position in symptomaticpatients. Dentomaxillofacial Radiology 2012; 41(5): 367-72.
10. M. A. H. Nahla, E. F. A. Tarek. MRI evaluation of TMJ internal derangement: Degree of anterior disc displacement correlated with other TMJ soft tissue and osseous abnormalities. The Egyptian Journal of Radiology andNuclear Medicine 2014 ; 735-44.

11. Matsumoto K, Kameoka S, Amemiya T, Yamada $\mathrm{H}$, Araki M, Iwai K, et al. Discrepancy of coronal morphology between mandibular condyle and fossa is related to pathogenesis of anterior disk displacement of the temporomandibular joint. Oral Surg Oral Med Oral Pathol Oral Radiol 2013; 116: 626-32. 